\title{
Modeling and Design of Graphene GaAs Junction Solar Cell
}

\author{
Yawei Kuang, Yushen Liu, Yulong Ma, Jing Xu, Xifeng Yang, \\ Xuekun Hong, and Jinfu Feng
}

School of Physics and Electronic Engineering, Changshu Institute of Technology, Changshu 215500, China

Correspondence should be addressed to Jinfu Feng; fengjinfu@cslg.cn

Received 28 November 2014; Accepted 31 December 2014

Academic Editor: Wen Lei

Copyright (C) 2015 Yawei Kuang et al. This is an open access article distributed under the Creative Commons Attribution License, which permits unrestricted use, distribution, and reproduction in any medium, provided the original work is properly cited.

\begin{abstract}
Graphene based GaAs junction solar cell is modeled and investigated by Silvaco TCAD tools. The photovoltaic behaviors have been investigated considering structure and process parameters such as substrate thickness, dependence between graphene work function and transmittance, and n-type doping concentration in GaAs. The results show that the most effective region for photo photogenerated carriers locates very close to the interface under light illumination. Comprehensive technological design for junction yields a significant improvement of power conversion efficiency from $0.772 \%$ to $2.218 \%$. These results are in good agreement with the reported experimental work.
\end{abstract}

\section{Introduction}

Graphene, a single atom layer of carbon hexagons, has attracted much attention owing to its unique structure and fascination, such as low resistivity, ultra-high mobility, and near-zero band gap [1]. Graphene has been produced in the form of ultrathin sheets consisting of one or a few atomic layers by chemical vapor deposition or mechanical exfoliation and can be transferred to various substrates, which open a wide field of potential applications such as high performance electronic devices, photosensors, and smart composite [2,3]. In particular the graphene film has a unique combination of high electrical conductivity and optical transparency in visible and near-infrared regions, which gives it the ability to serve as an active layer for metal-semiconductor $(\mathrm{M} / \mathrm{S})$ junction solar cells [4]. Recently, graphene based solar cells had been fabricated on various substrates such as Si [5], CdS [6], and GaAs [7]; much process has been achieved in the past several years. Moreover graphene/semiconductor nanowires heterojunction photoelectric devices have also been achieved [8], which is combined with the unique one-dimensional (1D) structural characteristics and versatile physical properties of 1D nanowires [9-12].

Graphene based junction solar cell could be fabricated at room temperature which shows great potential in light harvesting and conversion application with the advantage of low cost, facile processibility, and environmental amity. Li et al. reported the first graphene based silicon solar cell with the average power conversion efficiency of about $1.65 \%$ [13]. After this work, many effects have been exerted to improve the performance of solar cell by using silicon nanowire array [14], modifying the work function of graphene [15], chemical doping to graphene [16], and so forth. In comparison with currently widely used silicon substrate, GaAs has direct band gap and is highly resistant to radiation which makes it suitable for high efficiency solar cell design and space application. The present technique can also provide the possibility to combine large area graphene with GaAs $[17,18]$. Jie group transferred single and bilayer graphene sheets onto n-type GaAs substrates and got a power conversion efficiency of $1.95 \%$ [19]. Behura et al. calculated the photovoltaic response of graphene junction using the fundamental models for voltage and current; they pointed out that graphene GaAs heterojunction has a superior photovoltaic behavior to graphene silicon junctions [20].

However, the device based graphene GaAs junction is still far lower in efficiency. The application of graphene in solar cell requires much more investigation on devices especially in structure and technical parameter optimizing. In this work, simulation of graphene GaAs solar cells is carried out with 


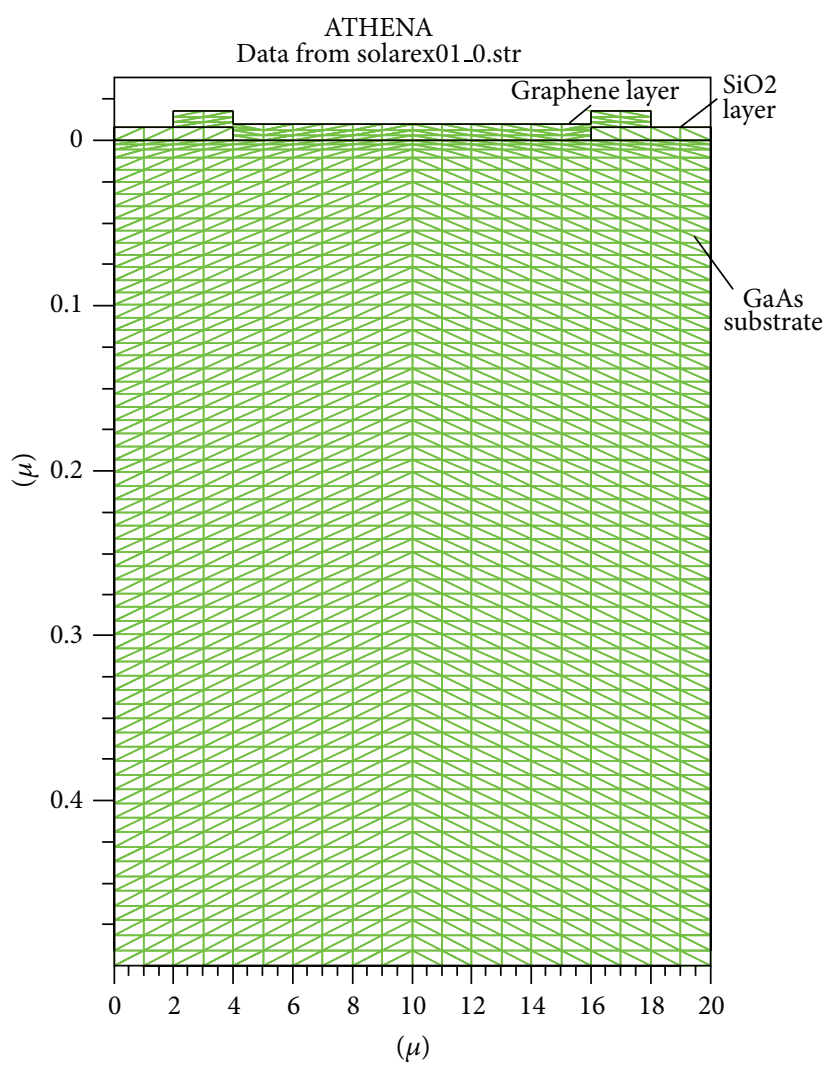

Figure 1: Cross section of the graphene GaAs solar cell.

the effect of substrate thickness, graphene transmittance and resistance, and n-type doping concentration. The graphene GaAs solar cell was modeled using Silvaco TCAD tools while the performance of solar cell was improved by parameter optimization.

\section{Structure and Modeling}

As mentioned above, Figure 1 shows the cross section of the graphene GaAs solar cell simulated using TCAD tools. The device consists of three regions which are Gallium arsenide (GaAs) substrate, $\mathrm{SiO}_{2}$ window layer, and graphene layer from bottom to the top area, respectively. Here the graphene layer with a thickness of $10 \mathrm{~nm}$ was coated onto the silicon substrate with $1 \mu \mathrm{m} \times 12 \mu \mathrm{m}$ oxide window which could decrease the surface recombination.

Basically, any semiconductor can form a Schottky junction with a certain metal if their work function difference is big enough and the carrier density of the semiconductor is moderate [21]. GaAs, with a direct band gap of $1.42 \mathrm{ev}$, is a promising material for optoelectronic device application. Calculations' results indicate that graphene films form a Schottky junction with GaAs, which is favorable for producing a relatively large built-in field [22].

The nonlinear $I-V$ characteristic of the Schottky junction can be expressed by the thermionic emission model:

$$
I_{s}=A A^{*} T^{2} e^{-\phi_{B} / K T},
$$

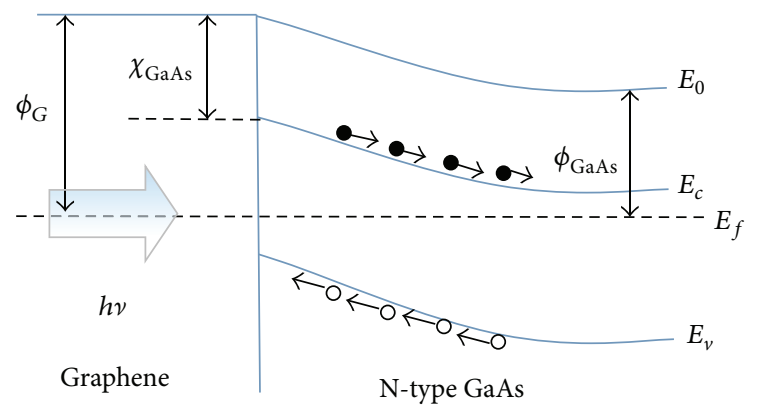

FIGURE 2: Energy diagrams of graphene n-GaAs solar sell.

where $A$ is the contact area, $A^{*}$ is the effective Richardson constant, $T$ is the absolute temperature, $K$ is Boltzmann constant, and $\phi_{B}$ is the barrier height

$$
\phi_{B}=\phi_{G}-\chi
$$

for $n$-type semiconductor where $\phi_{G}$ is the work function of graphene and $\chi$ is the electron affinity of semiconductor.

Under illumination, the photoexcited electrons and holes are generated in the GaAs substrate and then separated by the built-in electric field at the Schottky junction. Electrons and holes are collected by bottom electrodes and graphene film which form a photovoltaic action for n-type GaAs as shown in Figure 2. 
TABLE 1: Simulation parameters for graphene GaAs solar cell.

\begin{tabular}{lcc}
\hline Parameter & Description & Value \\
\hline$E_{g}$ & GaAs band gap & $1.42 \mathrm{ev}$ \\
\hline$N_{c}$ & Effective density of states in CB & $4.35 e \times 10^{17} \mathrm{~cm}^{-3}$ \\
\hline$N_{v}$ & Effective density of states in VB & $8.16 e \times 10^{18} \mathrm{~cm}^{-3}$ \\
\hline$\chi$ & GaAs electron affinity & $4.07 \mathrm{ev}$ \\
\hline & GaAs electron mobility, $300 \mathrm{~K}[23]$ & No doping: $8000 \mathrm{~cm}^{2} / \mathrm{Vs}$ \\
$\mu_{e}$ & & N-type doping $1 \times 10^{14} \mathrm{~cm}^{-3}: 7300 \mathrm{~cm}^{2} / \mathrm{Vs}$ \\
& & N-type doping $1 \times 10^{15} \mathrm{~cm}^{-3}: 5900 \mathrm{~cm}^{2} / \mathrm{Vs}$ \\
& GaAs hole mobility, $300 \mathrm{~K}$ & N-type doping $1 \times 10^{16} \mathrm{~cm}^{-3}: 4600 \mathrm{~cm}^{2} / \mathrm{Vs}$ \\
\hline$\mu_{h}$ & & No doping: $400 \mathrm{~cm}^{2} / \mathrm{Vs}$ \\
& & N-type doping $1 \times 10^{14} \mathrm{~cm}^{-3}: 340 \mathrm{~cm}^{2} / \mathrm{Vs}$ \\
& & N-type doping $1 \times 10^{15} \mathrm{~cm}^{-3}: 302 \mathrm{~cm}^{2} / \mathrm{Vs}$
\end{tabular}

TABLE 2: Efficiency versus GaAs thickness, graphene work function and transmittance, and n-type doping concentration under AM1.5 illumination.

\begin{tabular}{lccccccc}
\hline $\begin{array}{l}\text { GaAs thickness } \\
(\mu \mathrm{m})\end{array}$ & $\begin{array}{c}\text { Graphene work function } \\
(\mathrm{ev})\end{array}$ & $\begin{array}{c}\text { Graphene transmittance } \\
(\%)\end{array}$ & $\begin{array}{c}\text { N-type } \\
\text { doping } \\
\left(\mathrm{cm}^{-3}\right)\end{array}$ & $\begin{array}{c}J_{\mathrm{sc}} \\
\left(\mathrm{mA} / \mathrm{cm}^{2}\right)\end{array}$ & $\begin{array}{c}V_{\mathrm{oc}} \\
(\mathrm{V})\end{array}$ & $\begin{array}{c}\mathrm{FF} \\
\eta(\%)\end{array}$ \\
\hline 1 & 4.55 & 93.1 & No doping & 7.082 & 0.255 & 0.344 & 0.772 \\
2 & 4.55 & 93.1 & No doping & 8.483 & 0.268 & 0.406 & 1.174 \\
5 & 4.55 & 93.1 & No doping & 8.261 & 0.281 & 0.473 & 1.392 \\
10 & 4.55 & 93.1 & No doping & 7.519 & 0.289 & 0.433 & 1.196 \\
5 & 4.4 & 95.4 & No doping & 8.613 & 0.263 & 0.451 & 1.298 \\
5 & 4.8 & 85.3 & No doping & 7.951 & 0.296 & 0.496 \\
5 & 4.8 & 85.3 & $1 e 14$ & 7.966 & 0.301 & 0.499 \\
5 & 4.8 & 85.3 & $1 e 15$ & 8.054 & 0.332 & 0.518 & 1.755 \\
5 & 4.8 & 85.3 & $1 e 16$ & 8.191 & 0.389 & 0.548 & 2.218 \\
\hline
\end{tabular}

To investigate the performance of graphene based solar cell, simulations were carried out using TCAD, which divides into two steps since there is not graphene default involved in the material declination. Firstly, we deposit $10 \mathrm{~nm}$ aluminum film as anode electrode instead of graphene film using ATHENA tool to generate the device structure. Secondly, we redefine the anode electrode material as graphene layer using ATLAS tool.

Graphene is modeled as a semimetal, a carrier mobility of $15,000 \mathrm{~cm}^{2} / \mathrm{Vs}$. The carrier densities were calculated by Fermi distribution and by adjusting the values of effective masses, a thickness of $10 \mathrm{~nm}$, and band gap such that the cattier densities agree with experimental results. It is important to point out that, for multilayer graphene film, the $E-K$ dispersion relationship is weakly parabolic rather than linear as in the case of monolayer graphene. Simulation parameters used in Atlas tool for this device are listed in Table 1.

\section{Result and Discussion}

3.1. GaAs Substrate Thickness Effect. GaAs crystal is chosen as absorption area. Graphene layer acts as a transparent electrode, that is, for the intensity of photogenerated carriers. A Schottky junction is built in for the difference between their work functions. Figures 3(a)-3(d) show the photogeneration rates of GaAs solar cell under AM1.5 illumination with depth for absorption layer were maintained at $1 \mu \mathrm{m}, 2 \mu \mathrm{m}$, $5 \mu \mathrm{m}$, and $10 \mu \mathrm{m}$, respectively. The light could be absorbed in barrier layer and inside the semiconductor. Both results show the most effective absorption area located in the surface attachment about $0.1 \mu \mathrm{m}$. Meanwhile, Figure 3(d) shows that $10 \mu \mathrm{m}$ thickness is enough for full spectrum absorption since the intensity of the photogenerated carriers dramatically reduces in the deep area of GaAs substrate.

To investigate the effect of GaAs thickness on the performance of solar cell, we calculate the current-voltage curves and internal quantum efficiency (IQE) shown in Figures 4 and 5, respectively. Most carriers are generated around the surface for GaAs under light illumination. At the condition of the thickness below $5 \mu \mathrm{m}$, the absorption of long wavelength photo is strengthened with the increase of thickness. In comparison the absorption of long wavelength photo decreases when the thickness at $5 \mu \mathrm{m}$ and $10 \mu \mathrm{m}$ expects the absorption peak at $870 \mathrm{~nm}$ which is according to the band energy level of GaAs. As a result, the light current gets a peak value versus different substrate thickness which leads to the biggest power conversion efficiency at $1.392 \%$ (listed in Table 2). 


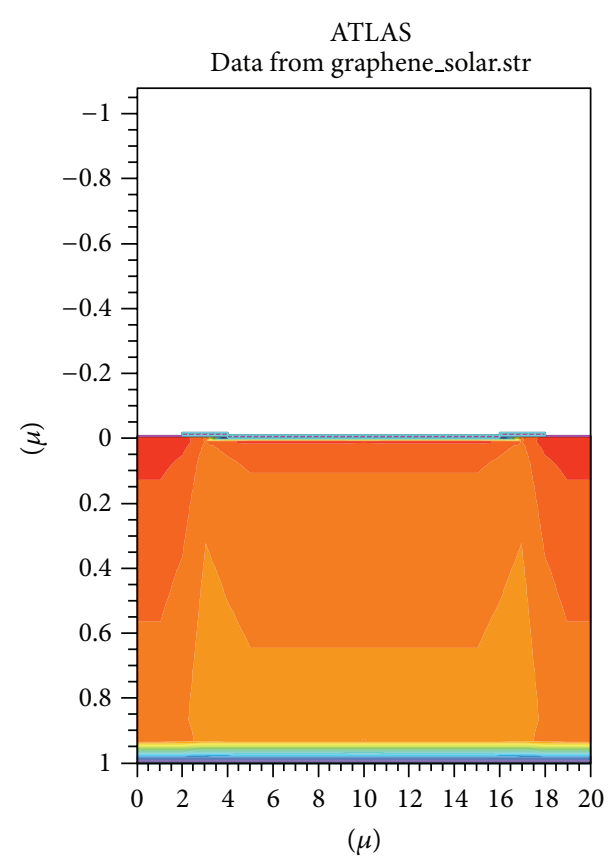

(a)

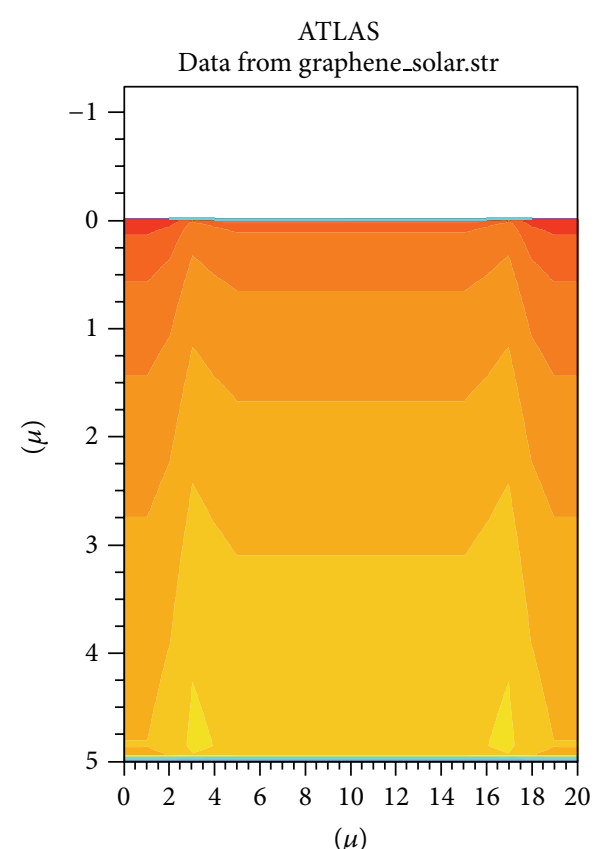

(c)

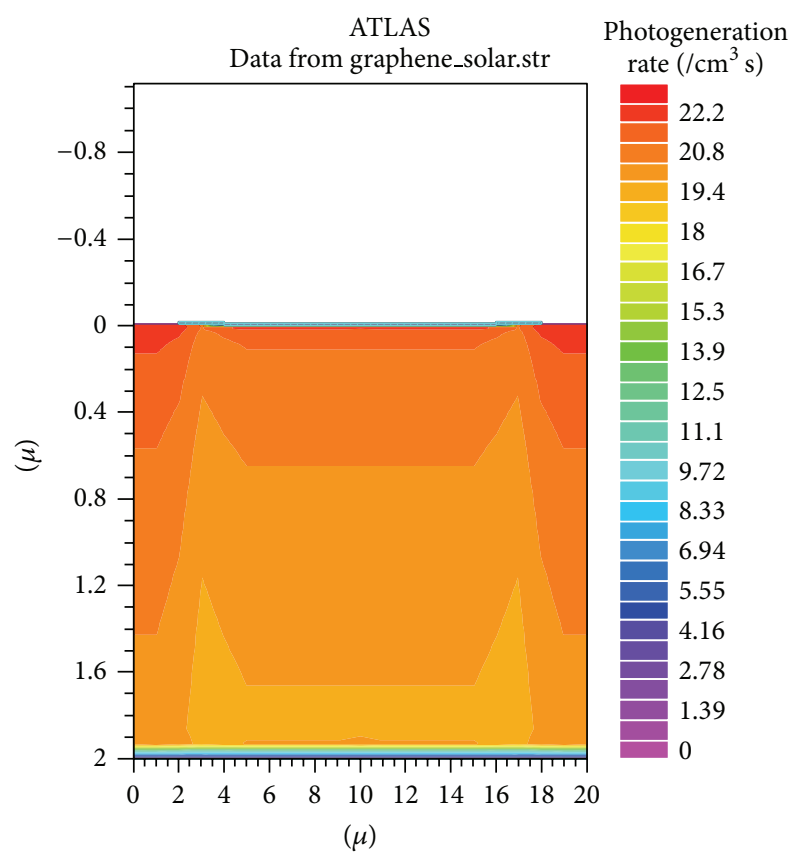

(b)

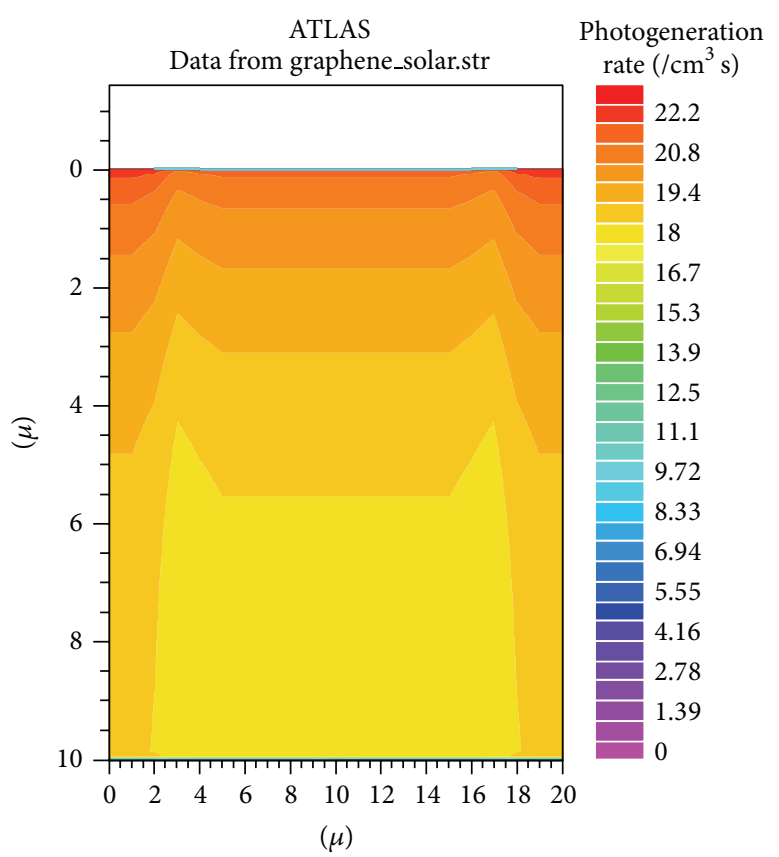

(d)

FigURE 3: Photogeneration rate of graphene GaAs solar cell under AM1.5 illumination versus substrate thickness: (a) $1 \mu \mathrm{m}$, (b) $2 \mu \mathrm{m}$, (c) $5 \mu \mathrm{m}$, and (d) $10 \mu \mathrm{m}$.

3.2. Graphene Work Function and Transmittance Effect. According to the theory model described in Figure 2, the battier height $\phi_{B}$ is related to the difference between graphene work function $\phi_{G}$ and electron affinity $\chi$ of GaAs. Consequently, higher work function increases $\phi_{B}$ and further enhances the built-in potential $V_{\mathrm{bi}}$ via the equation $V_{b i}=\phi_{B}-$ $V_{n}$, where $V_{n}$ means the distance between $E_{c}$ and $E_{f}$ in GaAs.
Therefore, the increase of graphene work function implies the increase of $V_{\mathrm{bi}}$ corresponding to the upper limitation of $V_{\mathrm{oc}}$.

Lancellotti et al. reported the dependence of graphene work function and transmittance on the number of layers [21]. We calculated the current-voltage curves and IQE of graphene GaAs solar cells versus different graphene work function considering the dependence of transmittance. 


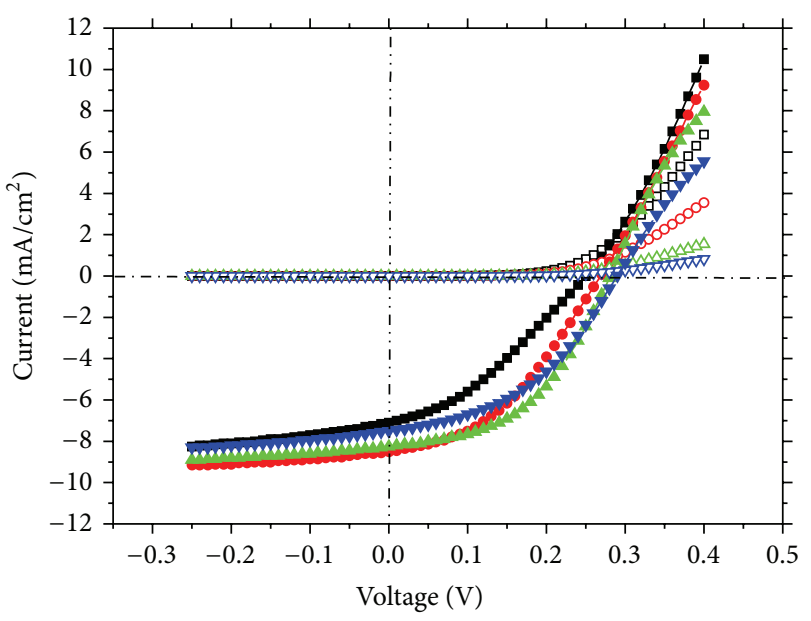

$$
\begin{array}{ll}
-\square-1 \mu \mathrm{m} \text { dark current } & -\Delta-5 \mu \mathrm{m} \text { dark current } \\
-\square-1 \mu \mathrm{m} \text { light current } & -\Delta-5 \mu \mathrm{m} \text { light current } \\
-\circ-2 \mu \mathrm{m} \text { dark current } & -\nabla-10 \mu \mathrm{m} \text { dark current } \\
-\bullet-2 \mu \mathrm{m} \text { light current } & -\nabla-10 \mu \mathrm{m} \text { light current }
\end{array}
$$

FIGURE 4: Current-voltage curves of graphene solar cells versus different GaAs thickness.

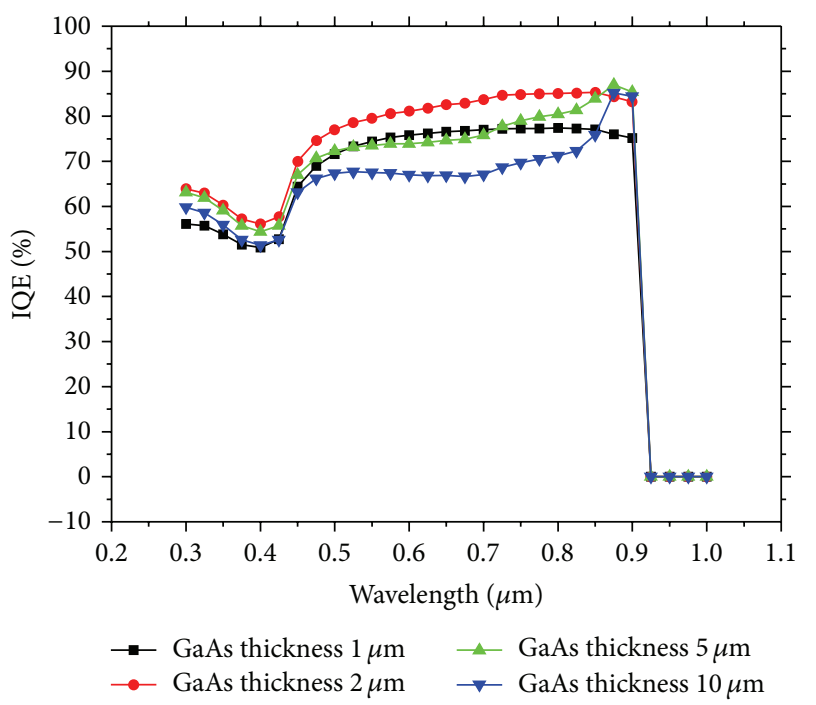

FIGURE 5: IQE of graphene solar cells versus different GaAs thickness.

We noticed that the IQE of three kinds of graphene layer have almost the same absorption spectrum zone as shown in Figure 7. However, the higher transmittance means the lower work function which leads to the balance between short circuit current and open-circuit voltage as shown in Figure 6. Accordingly, higher barrier also leads to a bigger fill factor. As a result, we got the biggest power conversion efficiency at $1.481 \%$ (listed in Table 2).

3.3. N-Type Doping Effect. It is well known that the n-type doping in GaAs can increase the Fermi energy level and intensity of photogeneration carriers. For doping concentration at $1 \times 10^{14} \mathrm{~cm}^{-3}, 1 \times 10^{15} \mathrm{~cm}^{-3}$, and $1 \times 10^{16} \mathrm{~cm}^{-3}$,

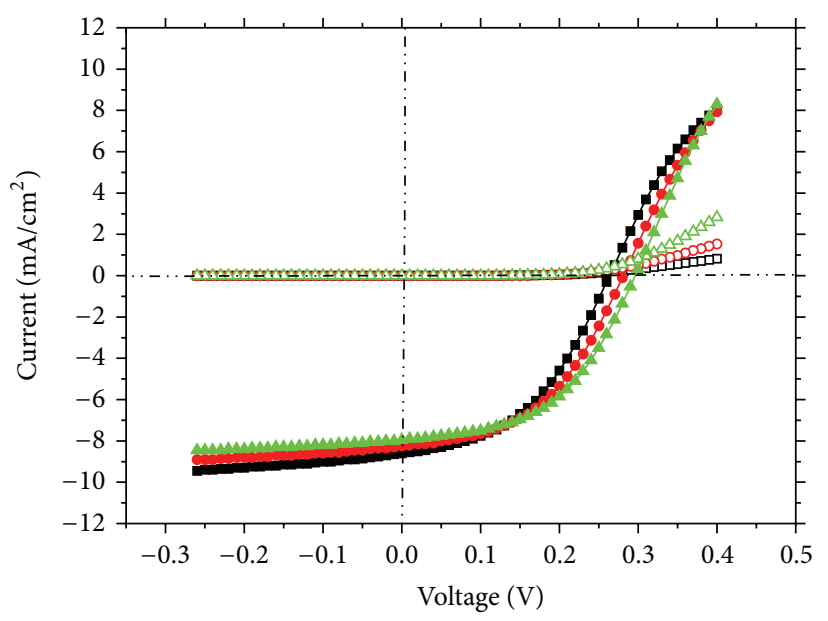

$\neg-$ Dark current graphene: 4.4 eV 95.4\%

$\rightarrow$ Light current graphene: $4.4 \mathrm{eV} 95.4 \%$

-o- Dark current graphene: $4.55 \mathrm{eV} 93.1 \%$

$\rightarrow$ Light current graphene: $4.55 \mathrm{eV} 93.1 \%$

$\triangle$ D Dark current graphene: $4.8 \mathrm{eV} 85.3 \%$

—— Light current graphene: $4.8 \mathrm{eV} 85.3 \%$

FIGURE 6: Current-voltage curves of graphene solar cells versus different graphene work function.

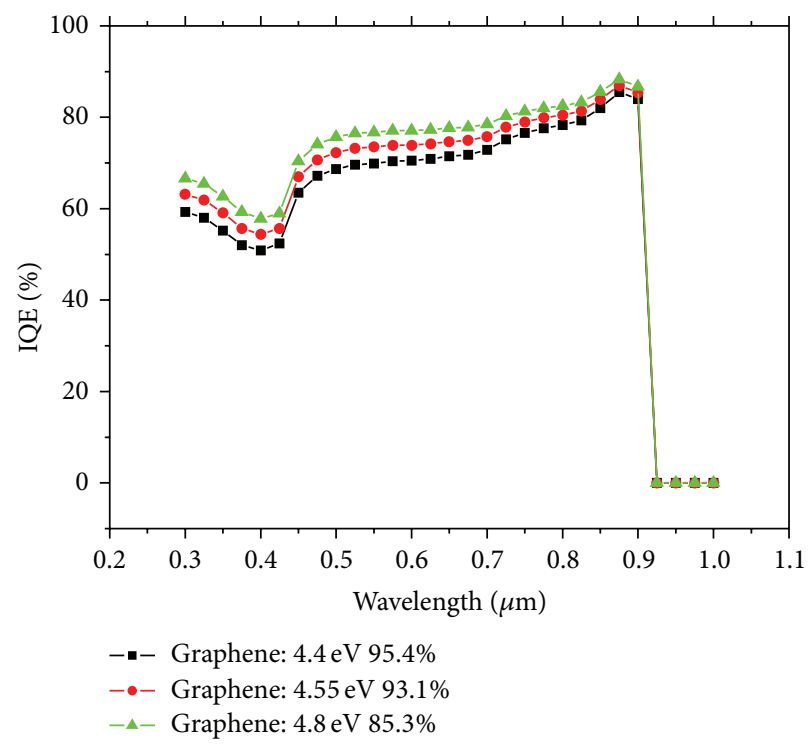

FIGURE 7: IQE of graphene solar cells versus different graphene work function.

the short-circuit current and open-circuit voltage are both increased due to higher barrier height as shown in Figure 8. The variation of $V_{\mathrm{oc}}$ is much more significant than that of $I_{\text {sc }}$ which has great consistency with the IQE results shown in Figure 9. In other words, n-type doping for GaAs mainly affects the height of barrier which leads to the enhancement of open-circuit voltage while the current generated by photos does not show great shifts. It may be due to the movement of depletion boundary in the region close to the interface of graphene and GaAs with increasing doping density. 


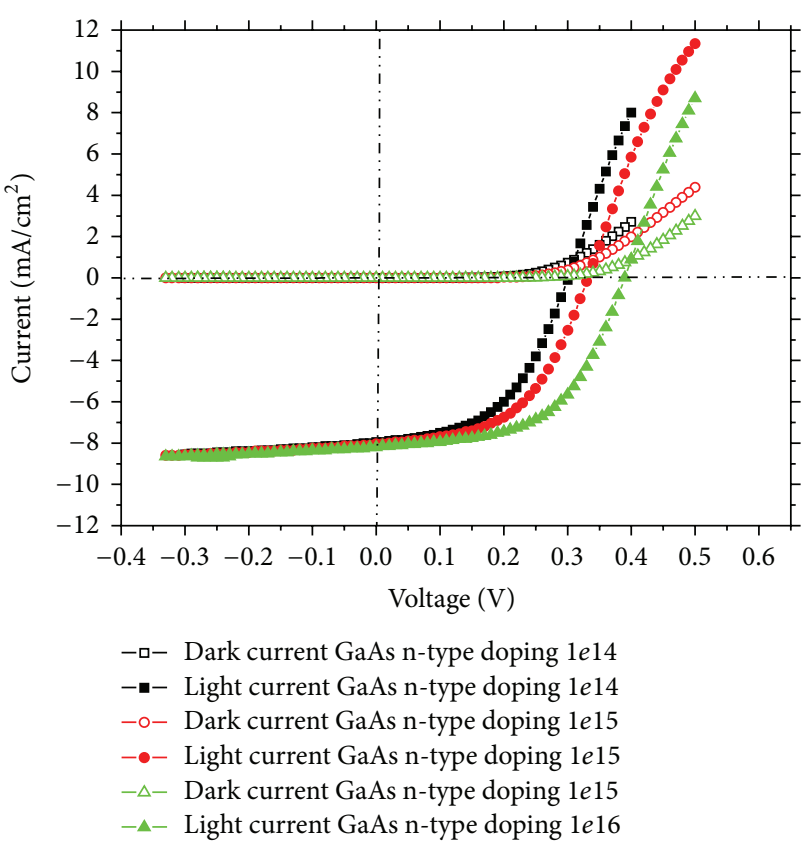

FIGURE 8: Current-voltage curves of graphene GaAs solar cells versus n-type doping concentration.

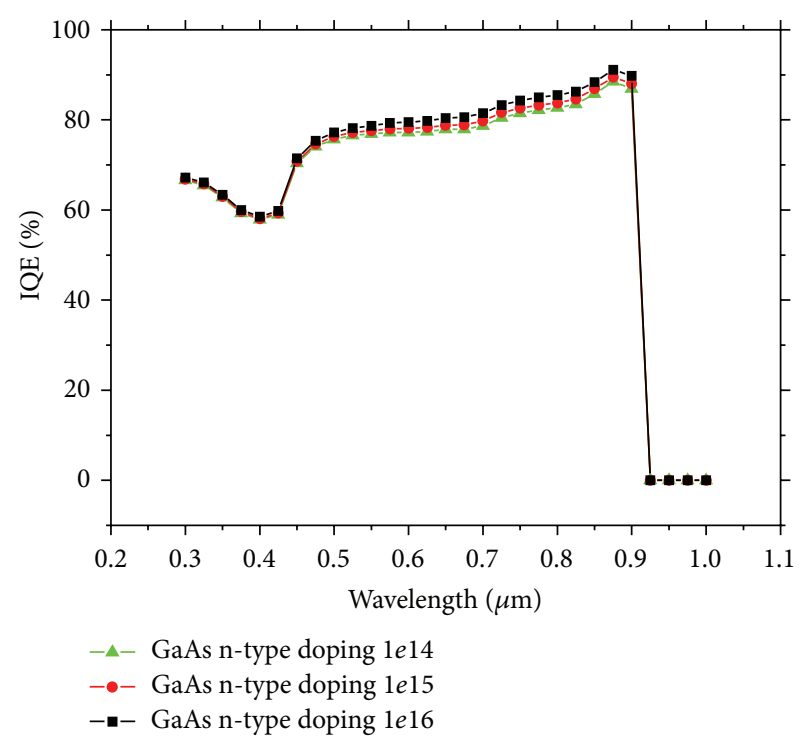

FIGURE 9: IQE of graphene GaAs solar cells versus n-type doping concentration.

\section{Conclusion}

Graphene based GaAs solar cell is modeled and then twodimensional simulation of this device is carried out using Silvaco TCAD tools. The process of structure generation and material definition is described in the front section. We further compared the performance at different conditions including GaAs thickness, graphene work function and transmittance, and n-type doping concentration in GaAs crystal in detail. The results show that most carriers generated in the region locate very close to the interface under light illumination. The comparison between higher work function and lower transmittance of graphene shows that the work function is more efficient for better performance. Moderate n-type doping in GaAs leads to great increase of power conversion efficiency while open-circuit voltage is much more sensitive than short-circuit current of this kind of device.

\section{Conflict of Interests}

The authors declare that there is no conflict of interests regarding the publication of this paper.

\section{Acknowledgment}

This work was supported by the National Natural Science Foundation of China (11247028).

\section{References}

[1] P. Avouris and M. Freitag, "Graphene photonics, plasmonics, and optoelectronics," IEEE Journal on Selected Topics in Quantum Electronics, vol. 20, no. 1, Article ID 6000112, 2014.

[2] D. Chen, H. Zhang, Y. Liu, and J. Li, "Graphene and its derivatives for the development of solar cells, photoelectrochemical, and photocatalytic applications," Energy and Environmental Science, vol. 6, no. 5, pp. 1362-1387, 2013.

[3] P. Gao, K. Ding, Y. Wang et al., "Crystalline Si/graphene quantum dots heterojunction solar cells," The Journal of Physical Chemistry C, vol. 118, no. 10, pp. 5164-5171, 2014.

[4] Z. Zhang, T. Cui, R. Lv et al., "Improved efficiency of Graphene/Si heterojunction solar cells by optimizing hydrocarbon feed rate," Journal of Nanomaterials, vol. 2014, Article ID 359305, 7 pages, 2014.

[5] X. Miao, S. Tongay, M. K. Petterson et al., "High efficiency graphene solar cells by chemical doping," Nano Letters, vol. 12, no. 6, pp. 2745-2750, 2012.

[6] Y. Lei, R. Li, F. Chen, and J. Xu, "Hydrothermal synthesis of graphene-CdS composites with improved photoelectric characteristics," Journal of Materials Science: Materials in Electronics, vol. 25, no. 7, pp. 3057-3061, 2014.

[7] L.-B. Luo, J.-J. Chen, M.-Z. Wang et al., "Near-infrared light photovoltaic detector based on GaAs nanocone array/monolayer graphene schottky junction," Advanced Functional Materials, vol. 24, no. 19, pp. 2794-2800, 2014.

[8] J. Miao, W. Hu, N. Guo et al., "High responsivity graphene/InAs nanowire heterojunction near-infrared photodetectors with distinct photocurrent on/off ratio," Small, 2014.

[9] Z. Liu, T. Luo, B. Liang et al., "High-detectivity InAs nanowire photodetectors with spectral response from ultraviolet to nearinfrared," Nano Research, vol. 6, no. 11, pp. 775-783, 2013.

[10] Z. Liu, J. Xu, D. Chen, and G. Shen, "Flexible electronics based on inorganic nanowires," Chemical Society Reviews, vol. 44, no. 1, pp. 161-192, 2015.

[11] N. Guo, W. Hu, L. Liao et al., "Anomalous and highly efficient InAs nanowire phototransistors based on majority carrier transport at room temperature," Advanced Materials, vol. 26, no. 48, pp. 8203-8209, 2014.

[12] J. Miao, W. Hu, N. Guo et al., "Single InAs nanowire roomtemperature near-infrared photodetectors," ACS Nano, vol. 8, no. 4, pp. 3628-3635, 2014. 
[13] X. Li, H. Zhu, K. Wang et al., "Graphene-on-silicon schottky junction solar cells," Advanced Materials, vol. 22, no. 25, pp. 2743-2748, 2010.

[14] X. Zhang, C. Xie, J. Jie, X. Zhang, Y. Wu, and W. Zhang, "High-efficiency graphene/Si nanoarray Schottky junction solar cells via surface modification and graphene doping," Journal of Materials Chemistry A, vol. 1, no. 22, pp. 6593-6601, 2013.

[15] T. Feng, D. Xie, Y. Lin et al., "Graphene based Schottky junction solar cells on patterned silicon-pillar-array substrate," Applied Physics Letters, vol. 99, no. 23, Article ID 233505, 2011.

[16] C. Xie, J. Jie, B. Nie et al., "Schottky solar cells based on graphene nanoribbon/multiple silicon nanowires junctions," Applied Physics Letters, vol. 100, no. 19, Article ID 193103, 2012.

[17] A. V. Babichev, V. E. Gasumyants, A. Y. Egorov, S. Vitusevich, and M. Tchernycheva, "Contact properties to CVD-graphene on GaAs substrates for optoelectronic applications," Nanotechnology, vol. 25, no. 33, Article ID 335707, 2014.

[18] K. Takehana, Y. Imanaka, T. Takamasu, Y. Kim, and K.-S. An, "Substrate dependence of cyclotron resonance on large-area CVD graphene," Current Applied Physics, vol. 14, no. 1, pp. S119S122, 2014.

[19] W. Jie, F. Zheng, and J. Hao, "Graphene gallium arsenide-based Schottky junction solar cells," Applied Physics Letters, vol. 103, no. 23, Article ID 233111, 2013.

[20] S. K. Behura, P. Mahala, A. Ray, I. Mukhopadhyay, and O. Jani, "Theoretical simulation of photovoltaic response of grapheneon-semiconductors," Applied Physics A, vol. 111, no. 4, pp. 11591163, 2013.

[21] L. Lancellotti, T. Polichetti, F. Ricciardella et al., "Graphene applications in Schottky barrier solar cells," Thin Solid Films, vol. 522, pp. 390-394, 2012.

[22] Z. Arefinia and A. Asgari, "A new modeling approach for graphene based silicon nanowire Schottky junction solar cells," Journal of Renewable and Sustainable Energy, vol. 6, no. 4, Article ID 043132, 2014.

[23] Silvaco-Atlas User's Manual, 2014. 

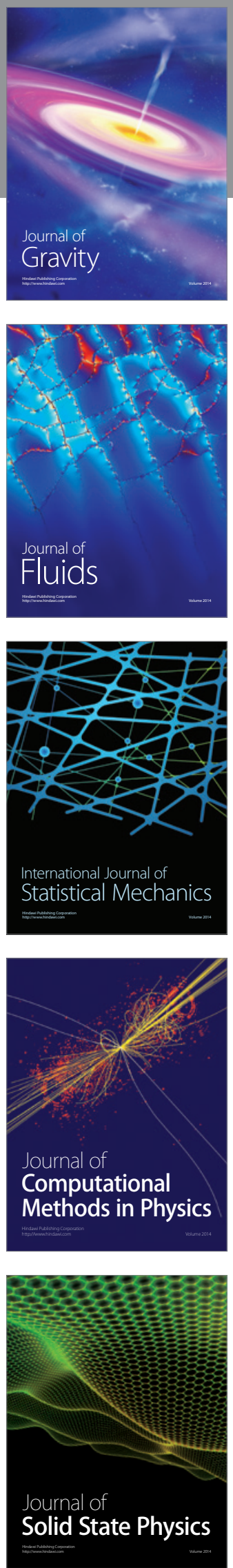

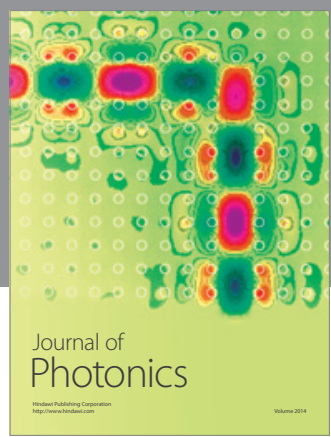

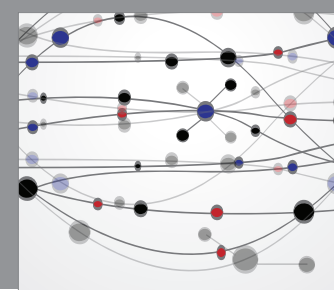

The Scientific World Journal

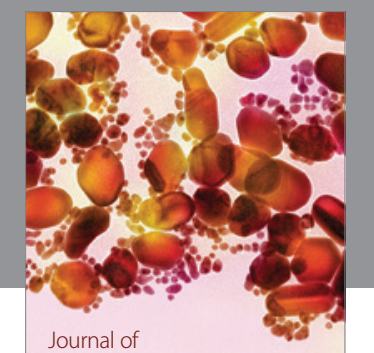

Soft Matter
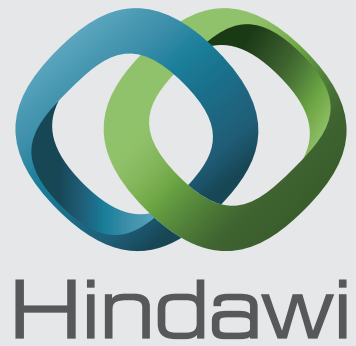

Submit your manuscripts at

http://www.hindawi.com
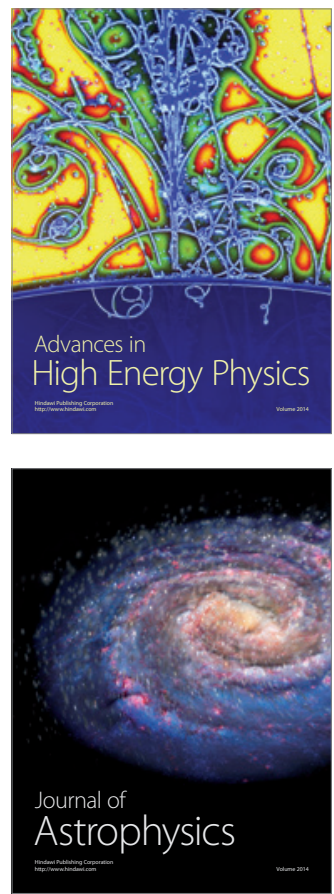
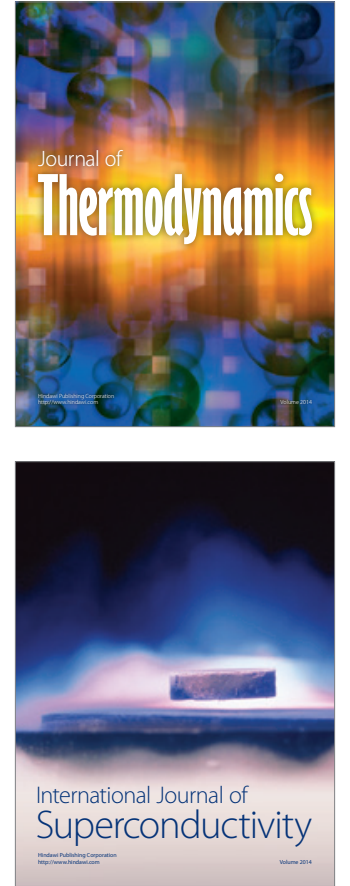
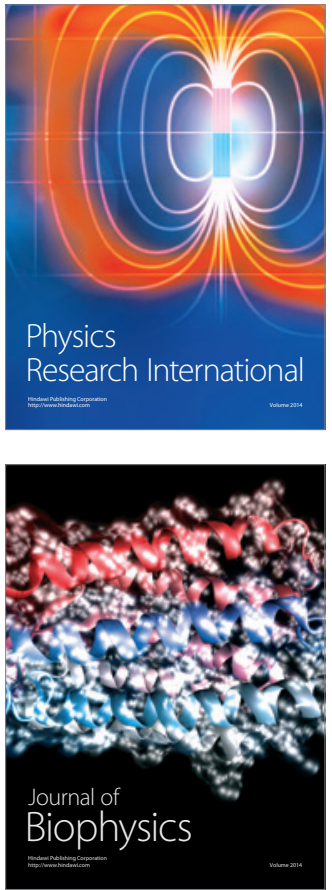
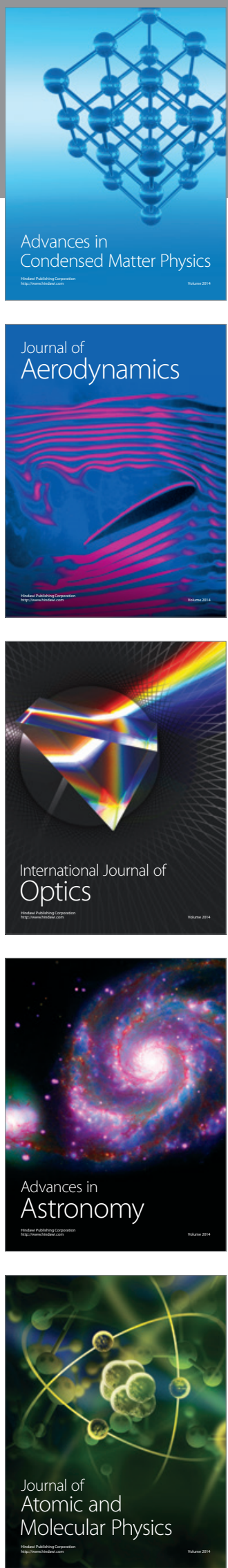